\title{
THE WIZARDS PROGRAM
}

\section{AT MERCY COLLEGE}

Boria Sax, Ph.D.

Director of Online Academic Services

Mercy College

555 Broadway

Dobbs Ferry, NY 10522

Phone: (914) 675-7397

Fax: (914) 674-7729

Email: BSax@Mercy.edu

\begin{abstract}
Mercy College has encouraged students to take a more active role in their education through the use of online teaching assistants or "course wizards." The duties of wizards include tutoring students, facilitating discussion, and locating resources, but their most essential function is to model the role of a successful student. Having successfully confronted the challenges of a college environment, they provide peers with the benefits of their experience. The program takes advantage of the special intimacy that students share with their classmates. This article gives an outline of the wizards program, and examines it with respect to several criteria including student satisfaction, learning effectiveness, faculty satisfaction, and the satisfaction of the wizards themselves.
\end{abstract}

\section{KEYWORDS}

Learner-Centered, Learning Community, Course Wizards

\section{TRADITION AND THE ONLINE CLASSROOM}

The traditional university classroom seems, at least superficially, to have changed remarkably little since the Middle Ages. Typically, today's teachers dominate the classroom at a large table or podium, and the pupils center around them.

Yet if the physical structure of the classroom has not changed, the content and dynamics certainly have. For one thing, knowledge has become so specialized over the past hundred years or so that scholars hesitate to make pronouncements beyond narrow areas of expertise. For another, the demographics of the classroom have changed dramatically. Where once there was a fairly homogeneous class of young men from privileged backgrounds, classes now contain a broad mix of ages, genders, and backgrounds [1]. The hierarchic elevation of the teacher is, therefore, not so easy to assume.

The anachronistic nature of this structure is dramatically evident in an online classroom. While the professor retains a certain authority, there are no conspicuous reminders of it. Everybody appears in essentially the same manner-as print on a screen [2]. The students learn not only from the professor but also from one another, as they submit questions and ideas to the entire group on discussion boards. The task of the instructor is primarily to structure and guide the learning process. 
In an online classroom, it is not enough for the professor to know an academic field or specialty; s/he must also have sophisticated technological and managerial skills. Teaching an online course generally requires more time than teaching a traditional one [3]. A bit like the proverbial housewife whose "work is never done," the online professor must be a provider of information, a skilled technician, and a role model. Fortunately, however, online technology also makes it easier for the professor to delegate some responsibilities.

To become successful students, learners also require complex skills, which must be modeled and developed. It is no longer sufficient for a student to simply follow the directions of the instructor. Students must be able to set their own goals, monitor their own progress, and, when necessarily, seek out help. Perhaps most importantly, students must interact not only with the instructor but also with one another, especially by participating in discussions [2, 3, 4]. As Peter Drucker has stated, "Increasingly, an 'educated person' will be somebody who has learned how to learn and who throughout his or her lifetime continues to learning ...especially...through formal education" [5]. Experience in traditional classrooms, in consequence, does not prepare either students or instructors very well for asynchronous learning networks.

\section{COURSE WIZARDS}

In general, the structure of an online class parallels that of a traditional one, with assigned papers, exams, and grades. The altered nature of the learning process, however, opens up new possibilities for organization of the classroom. The new tasks of the online classroom need not simply be assigned to the instructor or to the students, but may be divided up in novel ways.

When I assumed a job directing learning services at Mercy College, I noticed that online students would very often spontaneously offer or request help from one another. This heartening pattern, which I have not observed in traditional classrooms, is probably a consequence of the fact that students in the online classroom tend to communicate more with one another, rather than simply with the instructor. The use of course wizards was simply an attempt to systematically utilize this predisposition towards mutual assistance.

In 2000, the Online Campus at Mercy College began to restructure the traditional classroom in a manner appropriate to an online learning environment, through the use of online teaching assistants or "course wizards." Their duties include tutoring students, facilitating discussion, and locating resources, but their most essential function is to model the role of a successful student. Having successfully confronted the challenges of a college environment, they provide peers with the benefits of their experience. As students themselves, they enjoy a sort of trust and intimacy with members of the class that is generally not possible for faculty. Many course wizards also offer guidance to both students and faculty in the use of instructional software. They sometimes mediate between faculty and students, helping members of each group to appreciate the perspectives of the other.

Though they resemble the teaching assistant or "supplemental instructor" of the traditional classroom, the wizards differ in important respects. They are not simply representatives or assistants of the professor; they play a more active, autonomous, and independent role. The wizards do not engage in any activity related to grading, since that could add an unwanted element of tension in their working relationships with other students. While many online academic programs offer isolated services such as academic support, technical support, and guidance, the wizards program integrates these services in an original manner. It utilizes the unique credibility and understanding that students enjoy among their peers. 


\section{WIZARDS AND FACULTY SATISFACTION}

Having a wizard in the class can obviously save a faculty member a lot of time and effort, but the problem of online faculty satisfaction with wizards is not always simple. A faculty member will usually take both personal and professional pride in managing the classroom, and sharing this task on even a modest level can be a sensitive matter. Especially if they are not initially secure in an online environment, faculty members can feel that the very presence of a wizard is a challenge to their authority. They may also fail to understand the purpose of a wizard, and approach the wizard with inappropriate demands or expectations.

To deal with such issues requires good communication, tact, and sensitivity from all parties. Mercy's experience has been that the relationship between a wizard and a faculty member is likely to be most successful when a clear division of labor is established at the beginning of a course. This will allow the wizard to take initiative without appearing to abrogate the authority of the professor. The relationship of wizard and faculty member is nourished by continual discussions, and they should be in touch by email at least once a week.

Quite a few individual wizards have developed very close partnerships with wizards, which often continue from one term to the next. One faculty member, for example, wrote of her wizard at the conclusion of the fall 2000 term, "I feel so fortunate to have had her assistance - and I think all of my students would say the same! I really can't say enough good things about Jennifer: she is an extremely conscientious and caring individual whose enthusiastic participation in my course made a great difference to all involved."

In a survey conducted at Mercy College in fall semester of 2000, 93\% of faculty with wizards in their classes agreed that wizards had helped to facilitate class discussion. More than half of faculty gave wizards the highest rating for helpfulness on a scale of one to four [2]. In a survey of faculty who worked with wizards conducted at the end of the spring 2003 term, without exception all of the professors who responded said that they would like to have a wizard in future courses. When asked to rate the helpfulness of the wizard in their course on a scale of one to four, eight out of twelve, or 67\%, gave the wizard the highest rating of "very helpful." The remaining four, or 33\%, all gave the wizard the second highest rating of "moderately helpful." Not a single professor gave the wizard either of the two lowest ratings, which were "minimally helpful" or "not helpful at all."

Comments by faculty at the end of the spring 2003 semester were enthusiastic. One professor wrote, "One student referred to our wizard as the class 'guardian angel.' We know that angels can go where professors cannot! A wizard can be a sounding board, a clarifier, and a support for both student and instructor." Another observed that, "Although I strongly encourage my students to ask me if they have any questions, some students feel more comfortable asking another student for help." Some professors, however, qualified their praise for the wizard, by stating that the wizard's performance had not been consistent. One professor wrote, "Patricia was a good booster, was tough on lack of participation by students, and posted some thoughtful comments. I would have just liked more of all of these things from her. It was a tough class to motivate, to be sure."

\section{WIZARDS AND STUDENT SATISFACTION}

Nearly every professor in a traditional or online classroom has known the frustration of confronting an impassive row of faces. This lack of responsiveness can sometimes be at least as exasperating in an online classroom, where one cannot see the eyes of the students at all. Informal observation suggests that wizards can often help students overcome this passivity, and surveys confirm that student satisfaction with wizards is high. 
In a survey conducted at the end of the fall 2000 semester, we found that students in classes with wizards were more than two and a half times as likely to ask for help than those in classes without them, and virtually all students with wizards in their classes reported feeling "comfortable" in their course [2].

At the end of the spring 2003 term, we gave students who had been in classes with wizards an online survey and 57 responded. When were asked to rate the helpfulness of the messages posted by the wizards on class discussion boards on a scale of one to four, the overwhelming majority gave them the highest rating of "very helpful." The full results were as follows:

\begin{tabular}{|l|l|}
\hline 1. Very helpful & $68.4 \%$ \\
\hline 2. Moderately helpful & $19.3 \%$ \\
\hline 3. Somewhat helpful & $12.3 \%$ \\
\hline 4. Not helpful at all & $0 \%$ \\
\hline
\end{tabular}

Students were then asked to check ways in which the messages from the wizard may have helped them, and these were the results:

\begin{tabular}{|l|l|}
\hline Understand course material & $71.9 \%$ \\
\hline Understand the professor & $50.9 \%$ \\
\hline $\begin{array}{l}\text { Understand WebCT (Mercy College's learning } \\
\text { platform) }\end{array}$ & $47.4 \%$ \\
\hline Use the Internet for research & $38.6 \%$ \\
\hline Feel comfortable in college & $33.3 \%$ \\
\hline Messages didn't help & $3.5 \%$ \\
\hline Other & $10.5 \%$ \\
\hline
\end{tabular}

Perhaps the most important conclusion here is that the wizards addressed a very wide range of needs among the students.

\section{WIZARDS AND LEARNING EFFECTIVENESS}

A perennial difficulty of the Learning Center at Mercy and other institutions of higher education is that students, even when they are in danger of failing, have a great deal of difficulty in asking for help. Despite efforts by faculty and tutors to reassure them, students have often tended to view asking for help, or even accepting it, as a confession of failure. Surveys, especially at the end of the spring 2003 term, indicate that students are more likely to request help when there is a wizard in the course.

When asked whether they had requested individual help from the wizard in their course, $59.6 \%$ replied that they had. Of those who did not request individual help, $91.2 \%$ said that assistance was unnecessary. Only $2.9 \%$ said they did not contact the wizard because they felt shy or nervous. Not a single student said that it was because s/he didn't think of it or because the wizard did not seem helpful. Of those who contacted the wizard to request help, $88.2 \%$ gave the wizard the highest rating of "very helpful" on a scale of one to four, while $5.9 \%$ gave the second highest rating of "moderately helpful." 
Students were also asked to state in their own words what they liked best about the wizards program. The theme that came up most frequently was the security of knowing that somebody was always available to help in the event of difficulty. One student wrote of the wizard simply, "She was there to help. And she always made it known that she was available." Another wrote, "Well, it is good to have someone like Jenn who has taken the course. She is able to help out with every question or problem we may have. She was a patient and sympathetic wizard."

Students were also asked to state in their own words how the wizard program might be improved, but no single theme was mentioned consistently. Though a few students had criticisms of individual wizards such as relative slowness of response, virtually none of the criticism was directed at the structure of the program.

In the spring 2003 semester, we also set aside two sections of basic courses online, one with a wizard and one without, for comparison. The courses in each pair were otherwise as identical as possible, with the same syllabus and the same teacher. Each section had 19 to 20 students enrolled. One pair of courses was in history and the other in sociology. The average grade of the students in the courses without wizards, not counting withdrawals and incompletes, was 2.2 points or $\mathrm{C}+$, while the average grade in those with wizards was 2.8 or B-.

\section{WIZARD SATISFACTION}

Institutions of higher education are not likely to pay a dedicated wizard a salary commensurate with her efforts and skill. Mercy now pays wizards $\$ 1,000$ for each course per semester. Most faculty, when I tell them this, are startled that the wizards receive so much. I am often reminded that adjuncts often receive only about $\$ 1,500$ to $\$ 2,000$ per course, for everything from designing the syllabus to teaching and grading exams. The salary of the wizard comes to perhaps $\$ 10 / \mathrm{hr}$, which is only a little more than the norm for student wages.

To successfully run a wizard program, an administrator must offer other sorts of compensation beyond money to the wizards, and identifying these may take imagination. The rewards will, of course, include a valuable learning experience, which may be at times accompanied by academic credit. Mercy College is currently working on adding a training course in online education for the wizards, which is to be accompanied by certification in tutoring from the CRLA (College Reading and Learning Association). At times, being a wizard may also confer a certain status that extends beyond the classroom.

The most important reward for the wizards, however, is generally membership in a vital and supportive community. Together with Patricia Delgiudice, who coordinates the Mercy College Online Learning Center at Mercy College, I try to foster a strong sense of camaraderie among the wizards at Mercy College. When possible, we try to offer the wizards guidance and assistance with their careers. They are encouraged to share their hopes and frustrations not only with us but with one another. We have, for this purpose, set up a site on the web known as the Wizard's Corner, which includes a discussion list and useful links.

Perhaps, some day, the position of wizards may be professionalized and become a standard part of the online classroom. In the meanwhile, however, we have to encourage wizards to move on to regular employment eventually. Should they begin to think of being a wizard as a job, the good will that the program has engendered could easily give way to burnout. 
The level of motivation among wizards, however, has consistently been high. I cannot recall ever having had a student refuse an opportunity to be a wizard, and most of the wizards want to do as many courses as possible, usually for many semesters. Some wizards, to be sure, have at times neglected their work. In such cases Patricia and I have tried to offer extra guidance, but it has occasionally been necessary to remove the wizard from a course. Other wizards, however, have become so enthusiastically involved in their classroom activities that we must remind them to pace themselves, as they might otherwise be in danger of working themselves into exhaustion.

When asked what they found most rewarding in their work, wizards often mentioned the opportunity to make new discoveries and the satisfaction of helping students. As one of the wizards put it at the end of the fall 2002 term, "It feels good to know that the students will want to get to know you and that the professor wants to continue work with you. That means that I have done my share."

\section{CONCLUSION: THE FUTURE OF THE PROGRAM}

The wizards program is still only a few years old, and it is barely out of the experimental stage. Virtually all educational institutions, if they are to survive, become more structured over the years. The sense of novelty, and perhaps an initial spurt of enthusiasm, may be lost, but these can hopefully be compensated by greater efficiency. At this point, I am pleased to say that the program is becoming an integral part of the culture of Mercy College. We are now in the process of embarking on a joint endeavor with the University of Illinois at Springfield to refine and expand the program.

One variant of the program that we are planning to initiate is to have temporary wizards. These might be added to a class for a few days or weeks for such purposes as helping students with an important paper or encouraging class discussion. We are also looking at ways of adapting the wizards program to blended or to traditional classes. The basic concept behind the wizards is a very simple one, which is capable of almost endless variations - to give students more active roles in their own education.

\section{REFERENCES}

1. Rhodes, F. H. T. The Creation of the Future: The Role of the American University. Ithaca: Cornell UP, 2001.

2. Sax, B. New Roles for Tutors in an Online Classroom. Journal of College Reading and Learning. 33 (1): 62-67 (Fall 2002).

3. Palloff, R. M. \& Pratt K. Lessons from the Cyberspace Classroom: The Realities of Online Teaching. San Francisco: Jossey-Bass, 2001.

4. Moore, J. C. Elements of Quality: The Sloan-C Framework. Needham, MA: Sloan-C, 2001.

5. Drucker, P. F. Managing in a Time of Great Change. New York: Truman Talley/Dutton, 1995.

\section{ACKNOWLEDGEMENTS}

I would like to thank Dr. Stuart Cohen and David Alterman for invaluable help in formulating and implementing most of the surveys cited in this article. Dr. Frank McCluskey, the Dean of Online Learning at Mercy College has provided the institutional, as well as moral, support that made the wizards program possible. I am also grateful to Dr. Ellen Kreger, Assistant V. P. for Academic Support at Mercy College, who showed faith in the program through several crises. Patricia Delgiudice has helped to coordinate the wizards with great understanding and efficiency. Finally, we are grateful to AT\&T for a grant awarded in 2003, which has enabled us to continue and further refine the wizard's program. Most of all, I wish to thank the wizards themselves, though space does not allow me to list all of their names. 


\section{ABOUT THE AUTHOR}

Boria Sax, Ph.D. is best known as the author of many books about animals in human culture, two which have been named to the list of "outstanding academic titles of the year" compiled by the journal Choice: Animals and the Third Reich: Pets, Scapegoats, and the Holocaust (Continuum, 2000) and The Mythical Zoo: An Encyclopedia of Animals in Myth, Legend, and Literature (ABC-CLIO, 2002). He is founder of the organization Nature in Legend and Story (NILAS), dedicated to "promote understanding of traditional bonds between human beings and the natural world." Currently, he works as Director of Online Academic Services at Mercy College in Dobbs Ferry, NY. In 2002, he received the Sloan Consortium award for "online learning effectiveness," for founding the course wizard program. 